\title{
Correction: APR-246 reactivates mutant p53 by targeting cysteines 124 and 277
}

Qiang Zhang', Vladimir J. N. Bykov (1)', Klas G. Wiman (1) and Joanna Zawacka-Pankau²

\section{Correction to: Cell Death and Disease \\ https://doi.org/10.1038/s41419-018-0463-7, published online 18 April 2018}

Since publication of this article, the authors have noticed that there was an error in Fig. 1d, third panel from left, "R273H $+200 \mu \mathrm{M}$ MQ-H" should be "R273H $+200 \mu \mathrm{M}$ MQ". A corrected version of Fig. 1 is included here. Our corrections do not affect the original conclusions of this paper. The authors would like to apologize for any inconvenience caused.

Published online: 10 October 2019 


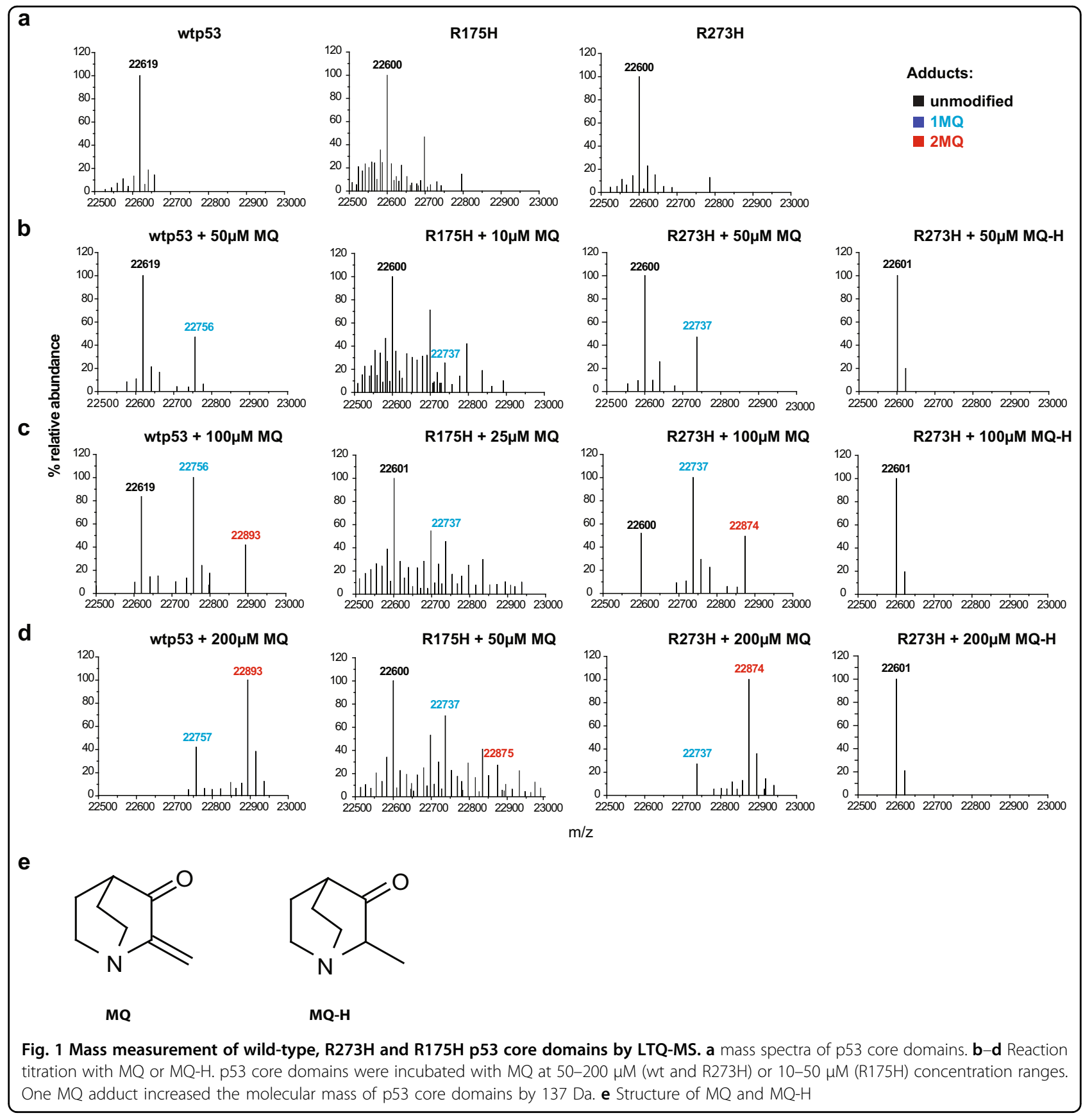

